\title{
MODELLING OF RAILWAY TRACK TEMPERATURE REGIME WITH REAL HEAT-TECHNICAL VALUES FOR DIFFERENT CLIMATIC CHARACTERISTICS
}

\author{
Stanislav HODÁS ${ }^{1 *}$, Alžbeta PULTZNEROVÁ ${ }^{1}$ \\ 1 Department of Railway Engineering and Track Management, Faculty of Civil Engineering, University \\ of Žilina, Univerzitná 8215/1, 01026 Žilina, Slovakia. \\ corresponding author: stanislav.hodas@fstav.uniza.sk.
}

\section{Abstract}

High quality of railway track construction is a major priority. One of the quality elements is the resistance to load of railway formation with individual structural layers caused by negative temperatures during the critical freezing period of winter. Numerical modelling allows obtaining more control outputs at different climatic loads. The presented paper shows the load of railway track model with different variants of climate and shows the importance in the designing of the non-transport load under negative temperatures, i.e. observation of transition of the zero isotherm through the layers of railway subgrade. If the subgrade layers of the railway formation are built with high quality and durability then the axis of the track will keep its geometric spatial position during the long-time operation.
\end{abstract}

\section{Keywords:}

Railway engineering; Layers of railway subgrade; Numerical modelling of temperature regime; Heat-technical values; Zero isotherm.

\section{Introduction}

The temperature regime in the particular structural layers of the railway track formation is one parameter of a set of characteristics with its assessment, mainly because the built-in materials have to resist the negative temperatures, i.e. then ensure the long-term deformation stability. In the different regions of the country, i.e. railway track location, there are different climatic conditions to which to the thickness of the structural layers and a selection of designed materials with increased of the frost resistance (and of course also to other influences) must be adapted. By numerical modelling the depth of freezing of the formation of railway construction and transition of temperatures through the particular layers of the used construction materials is being determined.

The Department of Railway Engineering and Track Management of Faculty of Civil Engineering at the University of Žilina (DRE-FCE-UNIZA) for a long time has been monitoring own made models of track in $1: 1$ scale since the year 2003 [1]. During the winter periods we observe the temperature values in the structural layers on points of the measurement positions and progressions of temperatures under different temperature loads in cold weather during freezing period are also detected. The values of numerical modelling by using the SV-HEAT SoilVision system [2] we can compare it with the measured values, but the advantage of the numerical modelling is that we can observe the model under different temperature loads [3].

The paper presents the results at the specified input climatic conditions from two models of long-term research at our department; the third model is a combination of them. Two more models are modelled under a climate with very cold weather. The paper presents models loaded with minimum temperatures at high minimum values of the frost index $I_{F}=-600$ to $-800^{\circ} \mathrm{C}$, which occur in our region Žilina, possibly Poprad, approx. 1 - 2 times in 30 years.

\section{Climatic characteristics}

On the basis of long-term research activities we use input data from some of the winter periods since 2013. The key to selecting there were two winter characteristics obtained, i.e. MODEL 1 - will be 
loaded by climatic temperatures of the period with the highest frost index during the reporting period from 2003 to 2017 [4], which is presented by the winter 2005/2006. MODEL 2 - climate from the period when the greatest depth $h_{F}$ of freezing construction layers was obtained and it was in winter 2011/2012 since 2003 [5]. The temperature load of the MODEL 3 was created by the combination of the lowest minus temperatures from MODEL 1 and MODEL 2 (Table 1 and Fig. 1). MODELS 1 to 3 are characteristic for the winter period of our regional area of Žilina for last 14 years (here also a global warming of the Earth plays partial influence).

Table 1: MODEL 1 to 3, years 2003 - 2017 at DRE-FCE-UNIZA - basic climate choice for modelling.

\begin{tabular}{|c|c|c|c|c|c|c|c|}
\hline \multirow{2}{*}{ WINTER } & $T_{M, a i r}$ & $T_{M, a i r}$ & $I_{F, \text { air }}$ & $I_{F, \text { sur }}$ & $h_{F}$ & \multirow{2}{*}{$\begin{array}{c}\text { Characteristics of the winter } \\
\text { period }\end{array}$} & \multirow{2}{*}{$\frac{\text { Snow }}{m}$} \\
\hline & $\max { }^{\circ} \mathrm{C}$ & $\min { }^{\circ} \mathrm{C}$ & $-{ }^{\circ} \mathbf{C}$ & $-{ }^{\circ} \mathbf{C}$ & $\mathbf{m}$ & & \\
\hline $\begin{array}{l}\text { 2005/06 } \\
\text { MODEL1 }\end{array}$ & 5.7 & -16.7 & 388 & $\underline{248}$ & 0.82 & $\left.\frac{\text { the highest frost index }}{\left(I_{F}^{\max }, I_{F, \text { surface }}\right.}{ }_{\text {max }}\right)$ & 0.05 \\
\hline $\begin{array}{c}\text { 2011/12 } \\
\text { MODEL2 }\end{array}$ & 4.9 & -15.2 & 238 & 207 & $\underline{0.89}$ & $\frac{\text { the maximum depth }}{\text { of freezing }\left(h_{F}^{\max }\right)}$ & 0.05 \\
\hline $\begin{array}{c}\text { 2005/12 } \\
\text { MODEL3 }\end{array}$ & \multicolumn{2}{|c|}{$\begin{array}{l}\text { climate } T_{s} \\
\text { model } 1+2\end{array}$} & $\underline{375}$ & \multicolumn{2}{|c|}{ Table 4} & $\begin{array}{l}\text { combination of } \\
\text { MODEL1 and MODEL2 }\end{array}$ & 0.10 \\
\hline
\end{tabular}

For purpose of subsequent modelling, we used the model with railway subgrade TYPE 2, which is processed in the Canadian software SV-HEAT [2]. All the following model situations are the same in terms of dimensions, material-technical characteristics of the layers, etc. [6]. In this proposed process of modelling, we can see the behaviour of the temperatures transition under different climatic loads. We expand our consideration to the MODEL 4, i.e. to our model built in laboratory, to which we will apply the climatic conditions of the mountain areas of the High Tatra Mountains, for the Poprad region. In the given location the frost index throughout the winter is usually $I_{F}=-500{ }^{\circ} \mathrm{C}$ and more, in our particular case in the winter $1995 / 1996$ it was $I_{F}=-600^{\circ} \mathrm{C}$, Table 2 . To illustrate the phenomenon we use the MODEL 5, which is based on the MODEL $3+30 \%$ up of the temperature, e.g. climate for frost index $I_{F}=-800{ }^{\circ} \mathrm{C}$, which generally occurs in long cycles of freezing with higher impact of frost (Table 2).

Table 2: MODEL 4 and 5, years 2003 - 2017 at DRE-FCE-UNIZA - further climate settings for modelling.

\begin{tabular}{|c|c|c|c|c|c|c|c|}
\hline \multirow{2}{*}{ WINTER } & $T_{M, a i r}$ & $T_{M, a i r}$ & $I_{F, \text { air }}$ & $I_{F, \text { sur }}$ & $h_{F}$ & \multirow{2}{*}{$\begin{array}{c}\text { Characteristics of the winter } \\
\text { period }\end{array}$} & \multirow{2}{*}{$\frac{\text { Snow }}{m}$} \\
\hline & $\max { }^{\circ} \mathrm{C}$ & $\min { }^{\circ} \mathrm{C}$ & $-{ }^{\circ} \mathbf{C}$ & $-{ }^{\circ} \mathrm{C}$ & m & & \\
\hline MODEL4 & \multicolumn{2}{|c|}{$\begin{array}{c}\text { climate } T_{s} \\
\text { model } 4\end{array}$} & $\underline{600}$ & \multicolumn{2}{|c|}{ Table 4} & $\frac{\text { original climate }}{\text { Poprad in 1995/96 }}$ & 0.15 \\
\hline MODEL5 & \multicolumn{2}{|c|}{$\begin{array}{c}\text { climate } T_{s} \\
\text { model } 5\end{array}$} & $\underline{800}$ & \multicolumn{2}{|c|}{ Table 4} & $\frac{\text { combination MODEL3 }+30 \%}{\text { Žilina - Slovakia }+30 \%}$ & 0.20 \\
\hline
\end{tabular}

The frost index $I_{F}$ is the sum of the negative daily temperatures $T_{s}$ during the winter period (each period begins when the first four days have minus temperatures). The average daily temperature $T_{s}$ is calculated daily from four daily measurements of $T_{s}=\left(T_{7 a m}+T_{2 p m}+2 . T_{9 p m}\right) / 4$, measured at $7 \mathrm{am}, 2 \mathrm{pm}$ and $9 \mathrm{pm}$. Particular detailed graphs for $T_{s}$ are shown in Fig. 1 and Fig. 2. The snow cover right in the track is in the individual models according to the Table 1 and Table 2 (we cannot ignore the fact that the train ride prevents the formation of snow layer higher than the railheads). 
a)

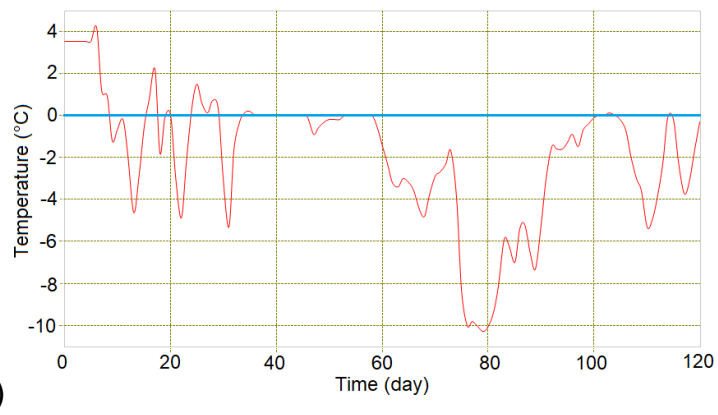

b)

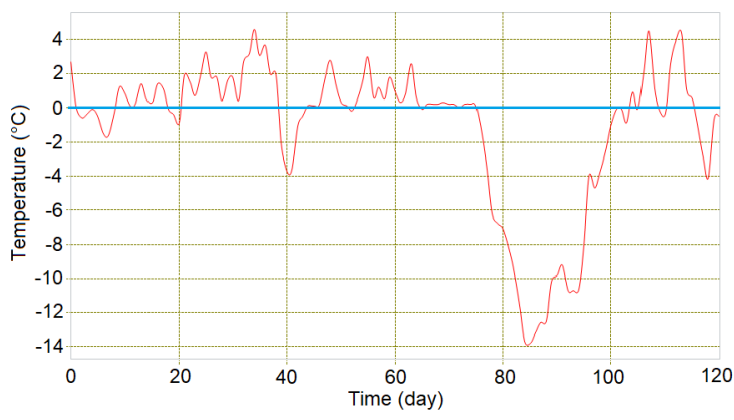

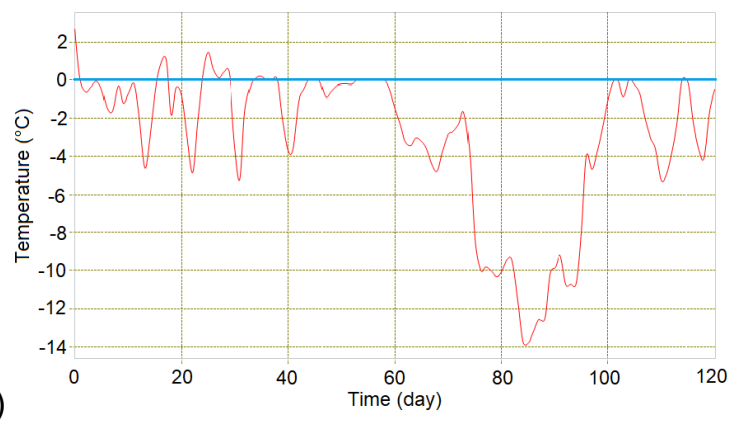

Fig. 1: Average daily temperature $T_{s}$ of MODEL 1 to 3 (120 days) - climatic loads.

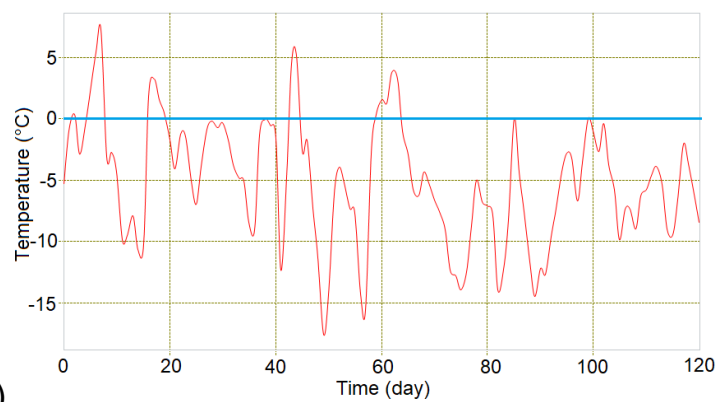

a)

Fig. 2: Average daily temperature $T_{s}$ of MODEL 4 and 5 (120 days) - climatic loads.

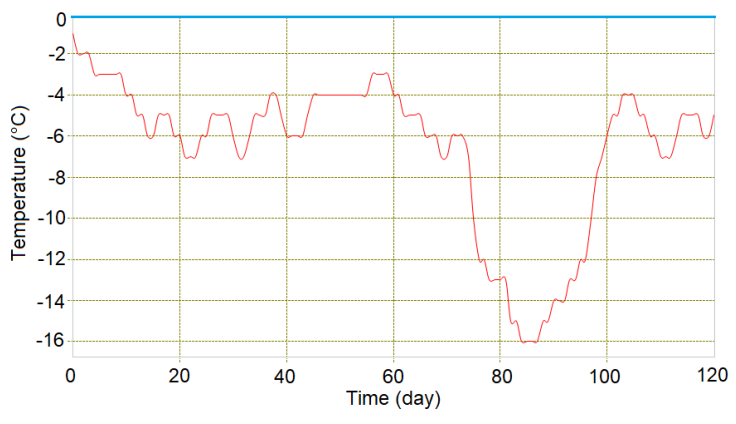

b)

20

The winter periods of each investigated winters of our research represent the duration of the 120 days period when frosts are expected, i.e. in the dates from November to March "10.11.( (year $\left._{i}\right)$ " to "10.3. $\left(\right.$ year $\left._{i+1}\right)$ ".

Northern Slovakia is situated at altitudes from 320 to $400 \mathrm{~m}$ above the sea level (Height system Balt settlement - Bpv.) with railway lines, such as the location of Žilina, where the presented models are built in the north of our country. The area of the town of Poprad is also in the north of the country (below the High Tatra Mountains at altitudes from 650 to $750 \mathrm{~m}$ above the sea level the Poprad railway station is located). To illustrate the height differences of the Slovak Republic, we will also mention Bratislava - the capital city of Slovakia, located at the height from 120 to $170 \mathrm{~m}$ above the sea level. Climate temperatures, which are now in the north of the country, were in the south about 25 to 40 years ago (global warming). For these reasons, it is necessary to consider at which altitude a railway line is built and which climate load the railway formation will resist (the research is focused on the winter periods and mainly freezing of the railway subgrade layers).

\section{Model loaded with minus temperatures}

The models are based on the built-in railway formation of the track in the "in-situ" DRETM laboratory [7] using SV-HEAT SoilVision [2]. The subbalast layers of the railway formation were modelled as the TYPE 2 of the railway subgrade with a protective gravel-sand layer under the track bed (the reason for its building-in is to increase its resistance to low freezing temperatures and also to improve the water regime of the layers). 
If the TYPE 1 of subgrade without protective layer was used, the railway subgrade could freeze at low $I_{F}$ values and we would have to consider its rebuilding to TYPE 2 in the given section of the track. In this paper, all climate changes are modelled already on the TYPE 2. Finally, we can conclude that with higher climatic loads due to external minus temperatures, we will also have to consider the TYPE 2 as partly freezing, because this sand-gravel protective layer have been freezing (at $I_{F}=$ $-600{ }^{\circ} \mathrm{C}$ and especially at $I_{F}=-800{ }^{\circ} \mathrm{C}$ ). It would be convenient to consider a greater thickness of the protective layer up to $600 \mathrm{~mm}$. One of other types of standard subgrades, TYPE 3 to TYPE 6, with other layers and structural elements, such as geotextile, geogrid, geocomposite, panels, asphalt, various stabilizing layers and so on, should be used in the structural design of the railway track to ensure non-freezing of railway substructure (these structures have also other properties, for example from the point of view of traffic load, and so on). The designer within designing can change the thickness of the particular layers and their structure by choice of built-in materials.

Better structure of the railway substructure, without various undesirable deformations and transformation from this inconvenient non-transport load from minus temperatures, can carry a better rail track (the traffic load from the axial pressures and the dynamics caused by the rail vehicles run are checked during the designing of the structural layers of the railway formation). The long-term sustainability of the correct geometric position of track and railway track objects will increase, and then the track will not require frequent refurbishment. TYPE 2 model is presented in Fig. 3 (it also applies to multi-line track with small changes in the course of temperatures in layers - stronger core of rail formation at high embankments and cuttings).

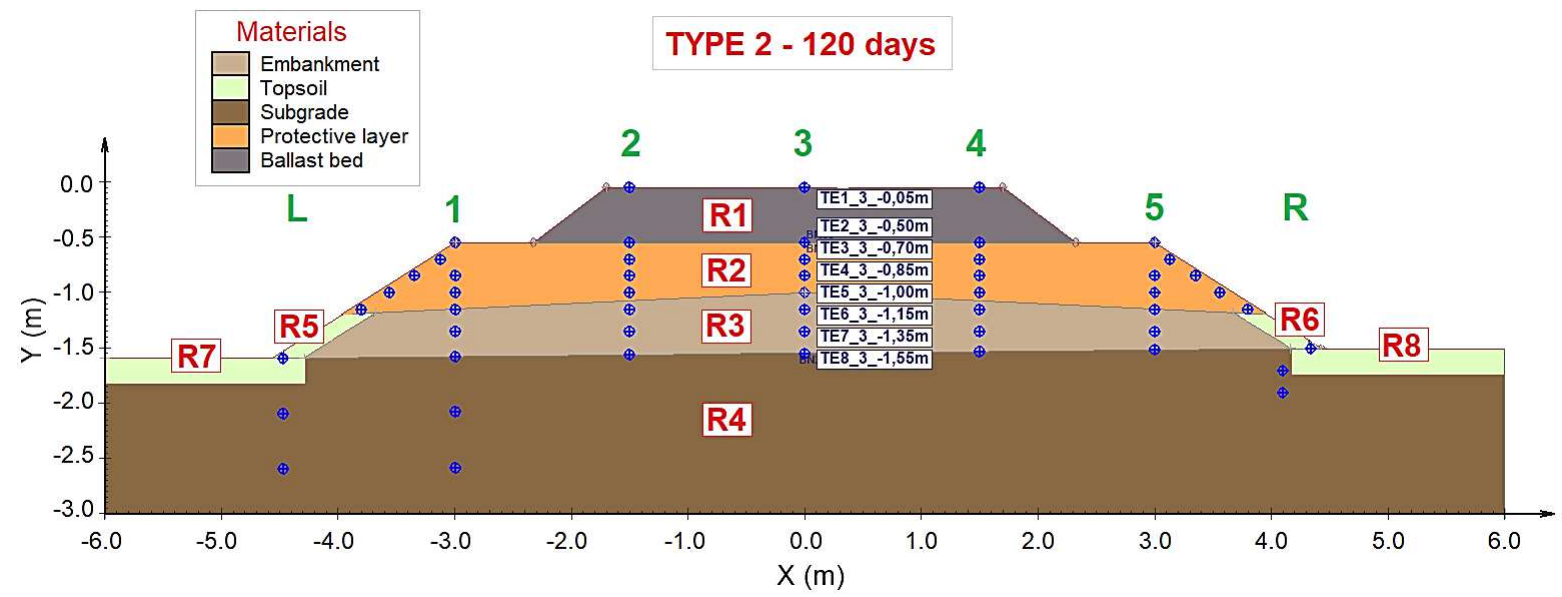

Fig. 3: Numerical model of subgrade profile TYPE 2 - part of railway track.

The railway track is modelled in the form of the construction areas $R_{i}$ (Fig. 3), i.e., of the particular layers in which the required structures of the materials with heat-technical parameters are built-in. The particular values of the technical characteristics of the model materials were determined by the laboratory tests at the accredited laboratory at the Department of Railway Engineering (DRE). The heat-technical characteristics of the materials of the subgrade of TYPE 2 from the "in situ" model have been inputted to our modelling (Table 3), [6], and [8], where: $\lambda$ - thermal conductivity, $\rho$ - soil dry density, $c$ - specific heat capacity, $T_{e f}$ and $T_{e p}$ - temperatures of freezing and thawing of the material, and $W$ - material humidity.

Table 3: Heat-technical characteristics of the layers of the railway subgrade model TYPE 2.

\begin{tabular}{|c|l|c|c|c|c|c|c|}
\hline \multirow{2}{*}{$\boldsymbol{R}_{\boldsymbol{i}}$} & \multirow{2}{*}{ Material } & $\boldsymbol{\lambda}$ & $\boldsymbol{\rho}$ & $\boldsymbol{c}$ & $\boldsymbol{T}_{\boldsymbol{e f}}$ & $\boldsymbol{T}_{\boldsymbol{e} \boldsymbol{p}}$ & $\boldsymbol{W}$ \\
\cline { 3 - 8 } & & $\mathbf{J} /($ day.m.C) & $\mathbf{k g} / \mathbf{m}^{3}$ & $\mathbf{J} /(\mathbf{k g} . \mathbf{C})$ & ${ }^{\circ} \mathbf{C}$ & ${ }^{\circ} \mathbf{C}$ & $\%$ \\
\hline R1 & Track bed & 58147 & 1908 & 980 & -0.01 & -0.5 & 1.3 \\
\hline R2 & Protected layer FPL & 145853 & 2045 & 1246 & -0.01 & -0.5 & 5.4 \\
\hline R3 & Embankment & 116166 & 2129 & 1216 & -0.01 & -0.5 & 5.5 \\
\hline R4 & Railway subgrade & 78710 & 1646 & 1495 & -0.05 & -1.5 & 18.0 \\
\hline R5 - R8 & Topsoil & 120960 & 1800 & 1000 & -0.01 & -0.5 & 20.0 \\
\hline
\end{tabular}




\section{Analysis of modelling results}

During the simulations of modelling, the results were analysed from the first day of the climate load (temperatures) automatically. At all given positions, analysis of freezing of the layers were performed simultaneously with the FlexPDE module in the system SV-HEAT [2]. For visual demonstration the positions of temperature measurement "TE_5_3_-1.00m" in Fig. 5 (the spatial position is in Fig. 3) are chosen, which is located at the decisive level of the railway substructure. The results presented in the figure are only after the complete analysis of the track model.

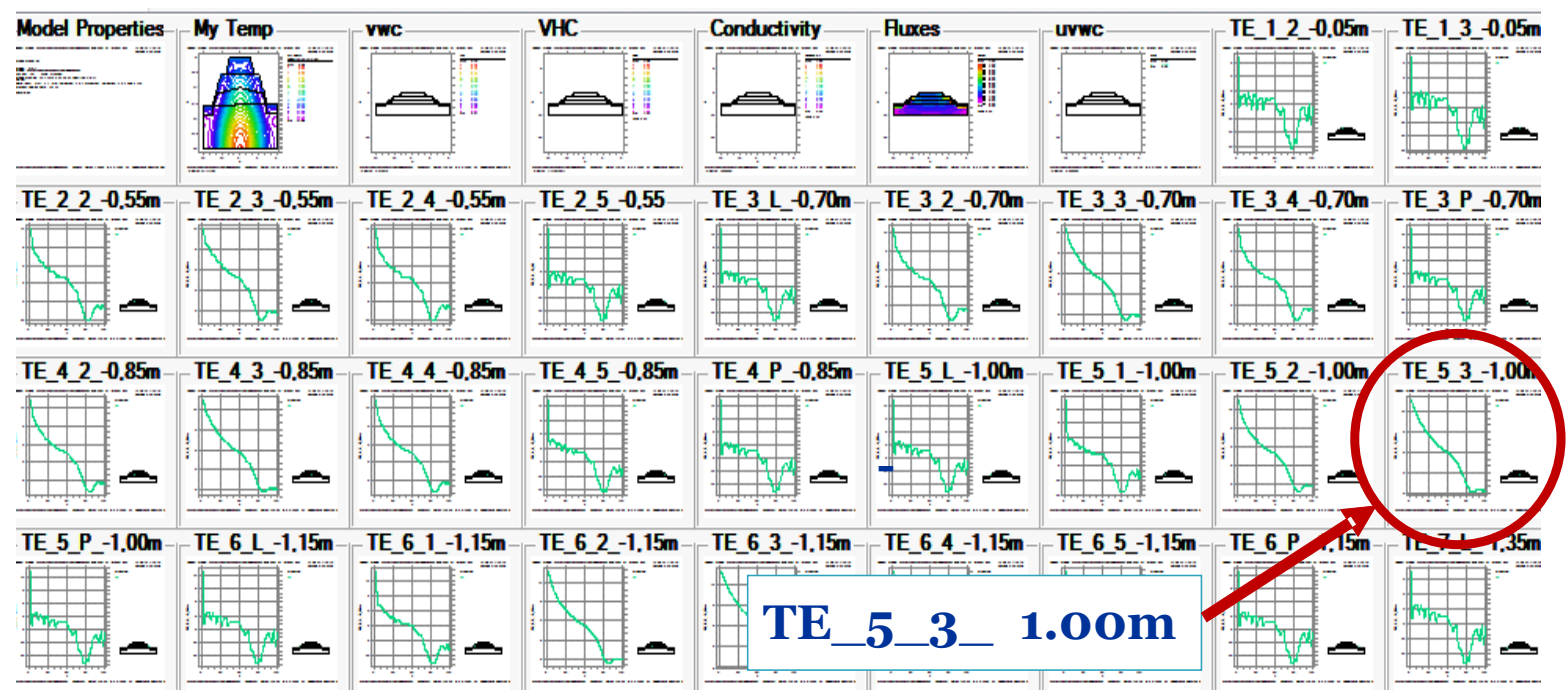

Fig. 4: Thermal analysis of the whole model and position "TE_5_3_-1.00m"-FlexPDE [2].

In the discussion we will analyse the course of temperatures at a specific point "TE_5_3_$1.00 \mathrm{~m}$ " (level in Fig. 3), which is located at the level of the railway substructure. In this case, we expect that the layer is not disturbed by the minus temperatures (i.e. we observe zero isotherm $-0{ }^{\circ} \mathrm{C}$ ) in the railway formation. Fig. 5 shows the results of temperature analysis after all climatic loads of MODEL 1 to 5 (Figs. 1 and 2).

Fig. 5 shows that in the MODEL 1 and 2 the freezing of the formation of the railway track subgrade does not occur on this point, but in the MODEL 3 its boundary is attacked by the zero isotherm $\left(0^{\circ} \mathrm{C}\right.$ limit). MODEL 4 and 5 show that under the given climatic loads $\left(I_{F}=-600{ }^{\circ} \mathrm{C}\right.$ and $I_{F}=$ $-800{ }^{\circ} \mathrm{C}$ ), the layer of the embankment of the railway formation under the protective layer will also be frozen $\left(F P L\right.$ - its thickness $\left.h_{F P L}=0.45 \mathrm{~m}\right)$. 

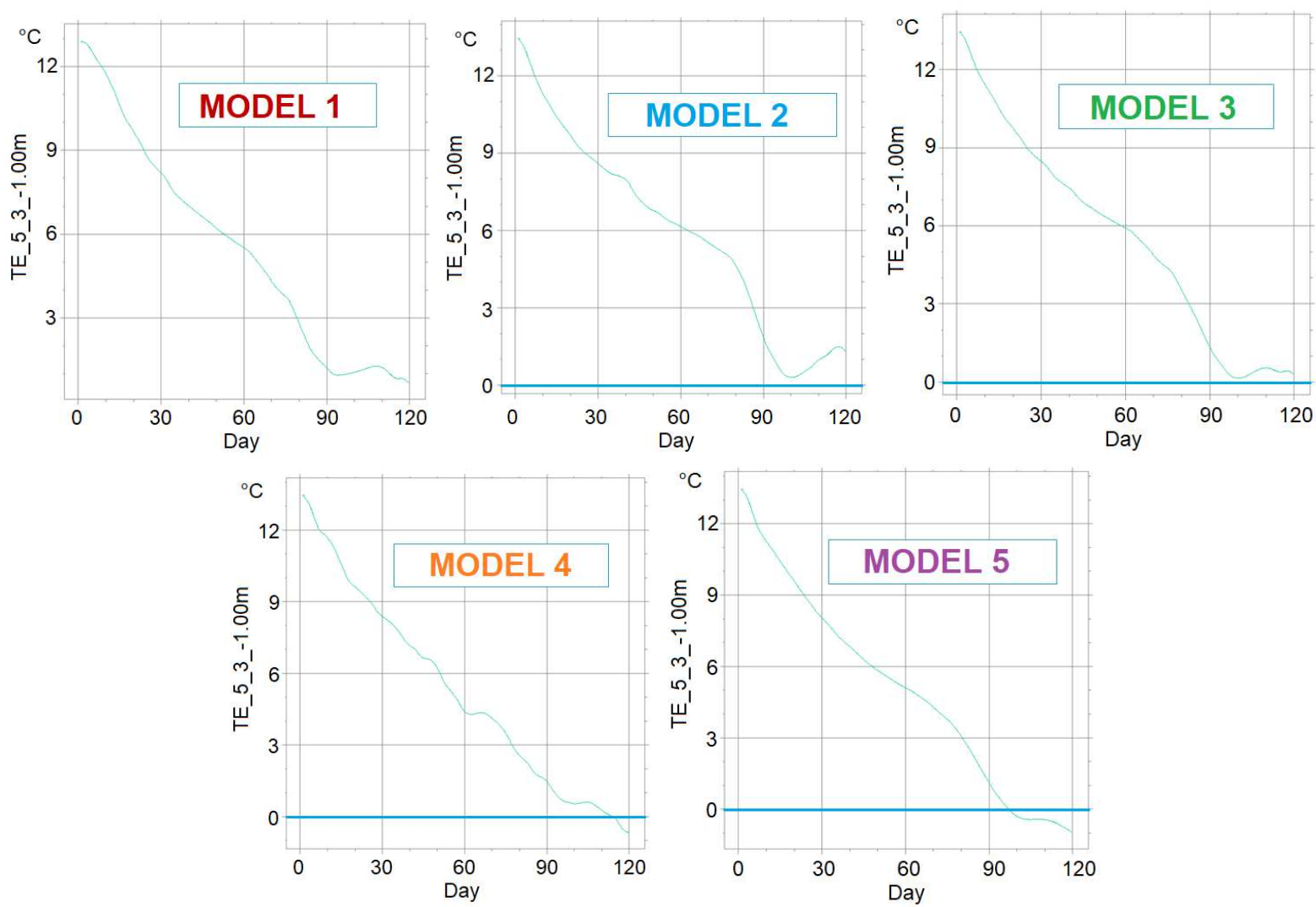

Fig. 5: The courses of the temperatures at the position "TE_5_3_-1.00 m" (Fig. 3): MODEL 1 to MODEL 5.

For this reason, it is necessary to protect the subgrade surface by adding new structural layers (geo-textiles, geo-materials, other material layers, etc.), or by increasing the thickness $h_{F P L}$ of the current protective sand-gravel layer, to ensure the required transition of temperatures through each layer of the railway body. Otherwise, we consider them to be partially freezing or unsuitable. The main task of the research was to find the maximum depth of freezing, i.e. the position of the zero isotherm, not only check of the individual measurements on positions during the analysis (eventually comparison with the temperature values from points of practical measurements "in-situ" on real models built by our department, [4]).

\section{Results of the analysis and conclusions}

Track modelling can be done in 2D or 3D SV-HEAT system [2]. The railway track is a transport construction of a line character and therefore we will do the analysis in 2D in the characteristic crosssection profile, because the whole section has the same character of the composition of the structural layers of the railway formation (the track in the longitudinal direction may be composed of consecutive multiple types of subgrade). In our case, the type of railway subgrade TYPE 2 is used throughout the track stationing. Similar considerations apply to the multi-line track (linking multiple analysed views next to each other).

Basically, from the analysis of the presented climate loads of the models it results (during 120 days of the winter period) that MODELS 1 to 3 are compliant with their temperature ranges up to frost index value of $I_{F 120} \leq-375^{\circ} \mathrm{C}$, where freezing of structural layers occurred up above the subgrade formation (whole railway bed and partly the protective sand-gravel layers), the depths of freezing were $h_{M O D E L 1}=0.60 \mathrm{~m}, h_{M O D E L 2}=0.70 \mathrm{~m}, h_{M O D E L 3}=0.95 \mathrm{~m}$, Fig. 6 . 

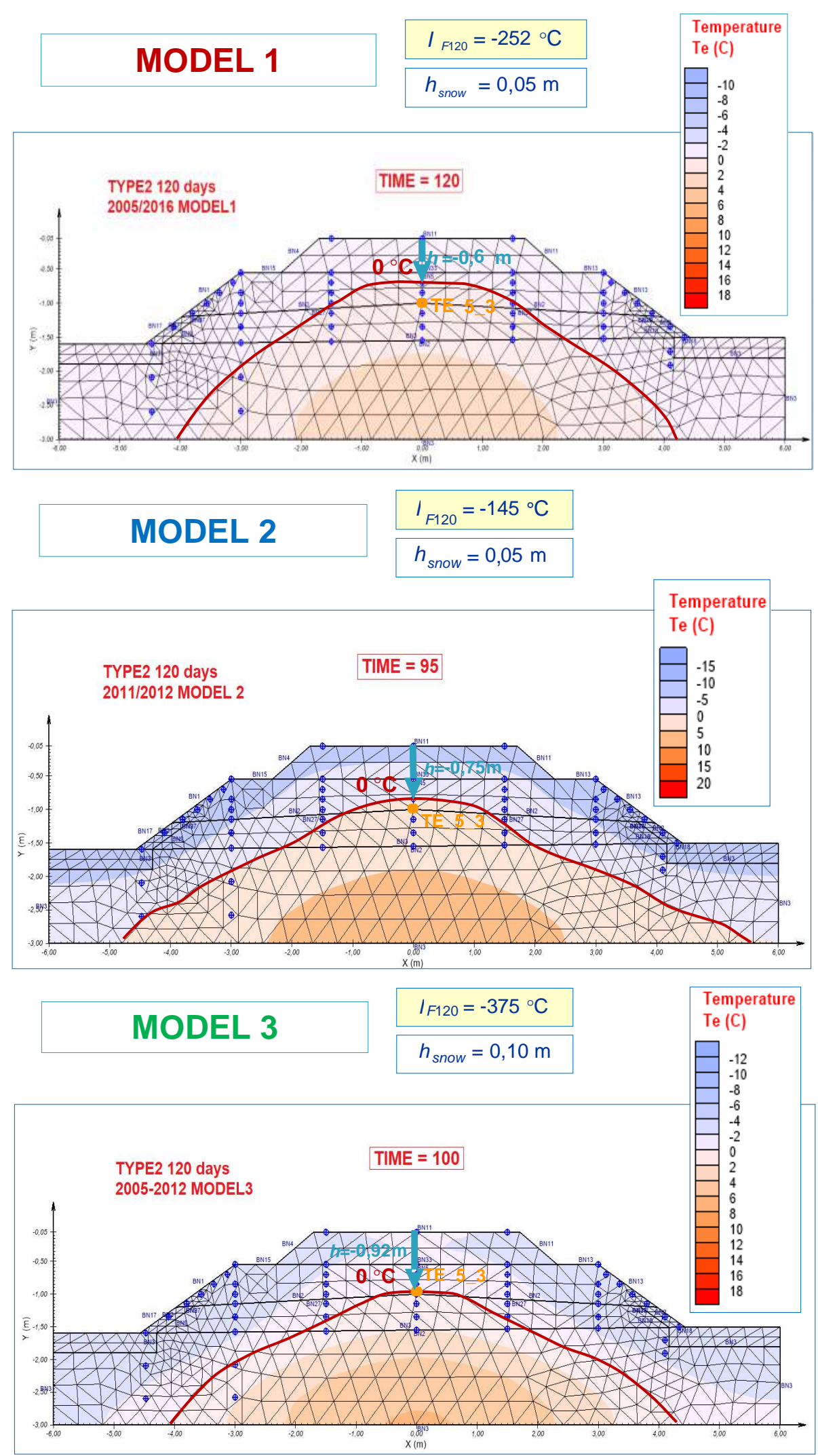

Fig. 6: Visualization of analysed results of modelling MODEL 1 to 3 -satisfactory.

Due to the effect of increased frost on structure in climate MODELS 4 and 5 with $I_{F p 120}=$ $-600{ }^{\circ} \mathrm{C}$ and $I_{F p 120}=-800{ }^{\circ} \mathrm{C}$ freezing of subgrade formation occurs in the analysed position „TE_5_3_$1,00 \mathrm{~m}$ ", which is evident in Fig. 7. The depths of freezing are $h_{M O D E L 4}=1.20 \mathrm{~m}$ and $h_{M O D E L 5}=1.35 \mathrm{~m}$. We can consider these structures to be partially freezing, or unsatisfactory (in the future, the railway 
formation will require more frequent interventions in maintenance of the track geometry, i.e. increase of maintenance costs during track operations on railway track, also [9] and etc.).

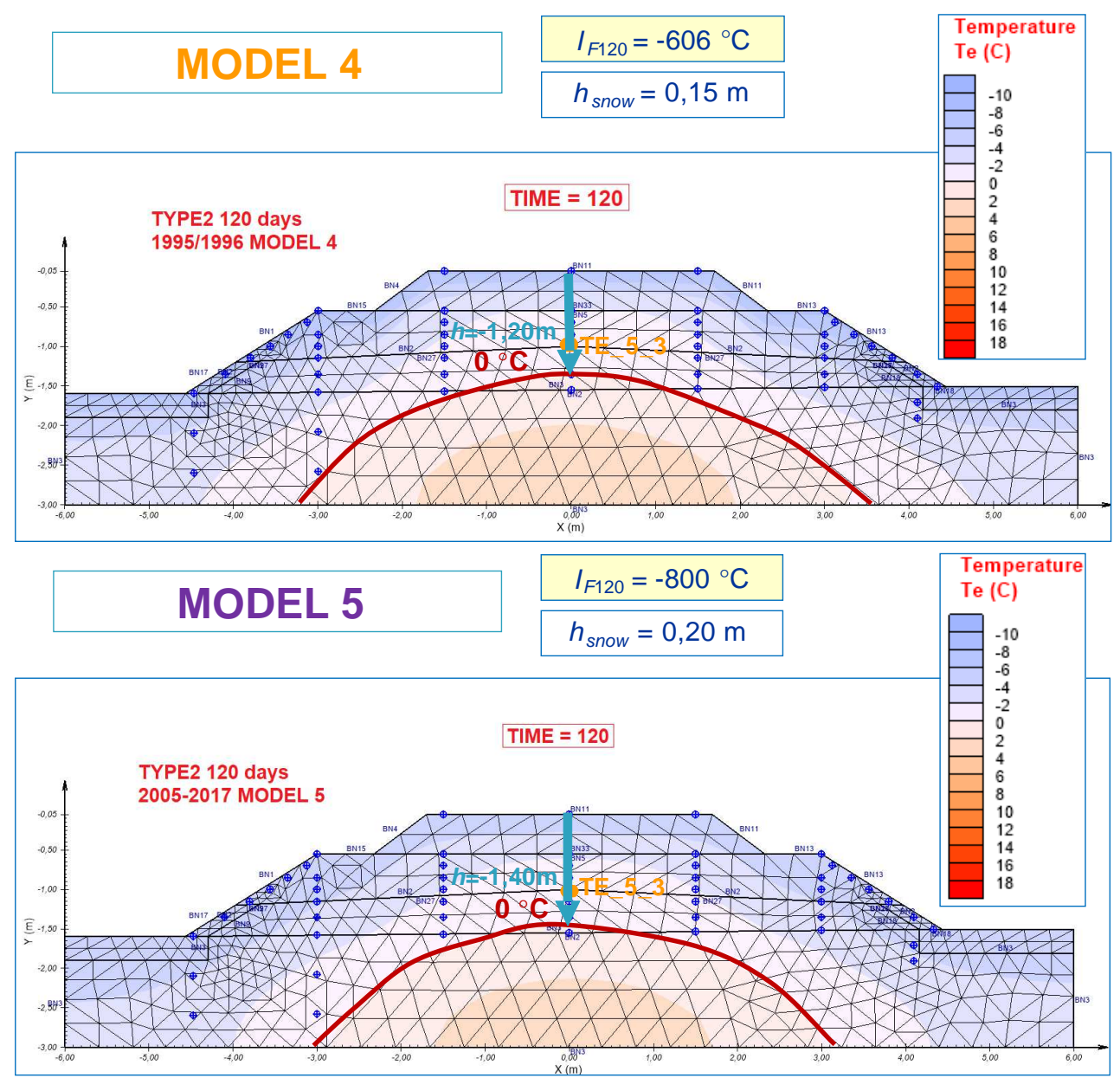

Fig. 7: Visualization of analysed results of modelling MODEL 4 and $5-$ unsatisfactory.

Table 4: Depths of freezing $h_{F}$ under different climatic loads.

\begin{tabular}{|c|c|c|c|c|c|}
\hline \multirow{3}{*}{ MODEL } & \multirow[b]{2}{*}{$I_{F, \text { air }}$} & \multirow[b]{2}{*}{ Climatic load } & \multirow{2}{*}{$\begin{array}{l}\text { Depth of } \\
\text { snow }\end{array}$} & \multicolumn{2}{|c|}{ Depth of freezing $h_{F}$} \\
\hline & & & & $\begin{array}{c}n_{F}=1 \\
I_{F, \text { air }}=I_{F, \text { surf }}\end{array}$ & $\begin{aligned} n_{F} & =0.85 \\
I_{F, \text { air }} & \neq I_{F, \text { surf }}\end{aligned}$ \\
\hline & $-{ }^{\circ} \mathrm{C}$ & Climate type & m & m & m \\
\hline MODEL1 & 400 & Clima1 (Fig. 1a) & 0.05 & 0.65 & 0.40 \\
\hline MODEL2 & 250 & Clima2 (Fig. 1b) & 0.05 & 0.86 & 0.72 \\
\hline MODEL3 & 375 & Clima3 (Fig. 1c) & 0.10 & 0.94 & 0.78 \\
\hline MODEL4 & 600 & Clima4 (Fig. 1d) & $\begin{array}{l}0.15 \\
0.20\end{array}$ & $\begin{array}{l}1.20 \\
0.91\end{array}$ & $\begin{array}{l}0.93 \\
0.63\end{array}$ \\
\hline MODEL5 & 800 & Clima5 (Fig. 1e) & $\begin{array}{l}0.20 \\
0.25\end{array}$ & $\begin{array}{l}1.45 \\
1.14\end{array}$ & $\begin{array}{l}1.09 \\
0.80\end{array}$ \\
\hline
\end{tabular}

In the case if the structures remained in these compositions of the layers and with the modelled thickness of the partial layers (MODEL 4 and MODEL 5 with high freezing index $I_{F}=-600$ to $-800{ }^{\circ} \mathrm{C}$ ), there may be deformations of railway subgrade, which also result in unacceptable behaviour of the layers above it, such as on the railway bed $\mathrm{R} 1$, on the protective sand-gravel layer $\mathrm{R} 2$, and so on. Subsequently, a disintegration of track geometry will occur (unsustainable horizontal and vertical position of the rail axis). The more the layers of the railway subgrade with the materials $\mathrm{R} 1$ to $\mathrm{R} 4$ will be deformed, the costs of repairing and reconstructing the section of the track will be increased 
(Table 4). These criteria are also integrated in the standard STN 73 6360-2: 2015 [10] as degrees: AL - assessment limit, IL - intervention limit (repair), and in the worst case as IAL - immediate action limit.

On the contrary, if we increase excessively the thickness of layers (i.e. overdesign), thereby we increase the investment costs for building the new lines, the reconstruction, the modernization or building of high-speed lines. The higher is the designed track speed, the higher are the quality requirements imposed on rail formation construction, and this applies in the context of non-transport load under minus temperatures, too.

\section{Acknowledgement}

The presented parts of the paper were created within the framework of the research activities of the Department of Railway Engineering at the Faculty of Civil Engineering at the University of Žilina (DRE-FCE-UNIZA) - VEGA 1/0275/16 Optimization design of sleeper subgrade due to non-traffic load aspect, 2016-2019 [1].

\section{References}

[1] VEGA 1/0275/16 Optimization design of sleeper subgrade due to non-traffic load aspect. Scientific research, Deparment of Railway Engineering, Faculty of Civil Engineering, University of Zilina, Žilina, http://svf.uniza.sk/kzsth. VEGA - Ministry of Education, Science \& Research of the Slovak Republic, Bratislava, SK, 2016-2019, http://www.minedu.sk/about-the-ministry/.

[2] SV-HEAT 2D/3D Finite Element - Freeze/Thaw Modelling. FlexPDE. 2017. SVOFFICE 2009 Geotechnical Modelling Suite, SVOFFICE ${ }^{\mathrm{TM}} 5 / \mathrm{GE} 2017$ - SV-HEAT ${ }^{\mathrm{TM}}$ GE. SoilVision systems Ltd., Saskatoon, Saskatchewan, Canada. http://www.soilvision.com.

[3] HODÁS, S. - IŽVOLT, L.: Modelling of temperature regime of railway track structure and its comparison with the results of experimental measurements. COMPRAIL XIV Railway engineering design and optimization, 19 - 21 July 2014, Rome, Italy, Edited by C.A. Brebbia, WESSEX Institute of Technology, http://www.wessex.ac.uk, WitPress, http://www.witpress.com, Southampton, United Kingdom, 2014, pp. 253-265.

[4] HODÁS, S. - IŽVOLT, L. - DOBEŠ, P.: Preliminary results and conclusions from mathematical modelling of thermal regime of railway track structure. International Journal of Computational Methods and Experimental Measurements, WESSEX Institute of Technology, http://www.wessex.ac.uk, WitPress, http://www.witpress.com, Southampton, UK, 4 (2), 2016, pp. 69-79.

[5] IŽVOLT, L. - DOBEŠ, P.: Mathematical modelling of the various factors impact on the frost depth of subgrade construction. Proceedings XXIV Russian - Slovak - Polish Seminar Theoretical Foundation of Civil Engineering, Samara, 2015, Procedia Engineering, Vol. 111, 2015, pp. 331338.

[6] IŽVOLT, L. - DOBEŠ, P. - MEČÁR, M.: Contribution to the Methodology of the determination of the Thermal Conductivity Coefficients $\lambda$ of Materials Applied in the Railway Submase Structure. Communications - Scientific Letters of the University of Žilina, Iss. 4, 2013, pp. 9-17.

[7] IŽVOLT, L. - DOBEŠ, P. - PITOŇÁK, M.: Some experience and preliminary conclusions from the experimental monitoring of temperature regime of subgrade structure. COMPRAIL 2014, pp. 267278.

[8] IŽVOLT, L. - DOBEŠ, P. - PULTZNEROVÁ, A.: Monitoring of moisture changes in the construction layers of the railway substructure body and its subgrade. Proceedings XXV. Russian - Slovak Polish Seminar Theoretical Foundation of Civil Engineering, Procedia Engineering, Vol. 161, 2016, pp. 1049-1056.

[9] ZVOLENSKÝ, P. - GRENČíK, J. - KAŠIAR, L'. - VOLNA, P. - LICCIARDELLO, R.: Modelling and experimental analysis of noise transmission through wall of a railway vehicle. Communications Scientific Letters of the University of Žilina, 2A/2017, Vol. 19, pp. 60-67.

[10] STN 73 6360-2:2015. Railway application. Track Part 2: Acceptance of construction works, maintenance works and assessment of service condition track gauge $1435 \mathrm{~mm}$. Standard of Slovak Railways, 2015. 